\title{
Chuyển quyền Các-bon, cơ chế quản lí tài chính và chia sẻ lợi ích liên quan đến chi trả dựa vào kết quả giảm phát thải
}

\section{Kinh nghiệm quốc tế và đề xuất cho Việt Nam}

\author{
Phạm Thu Thủy ${ }^{1}$, Nguyễn Thị Vân Anh'², Nguyễn Thị Thủy Anh ${ }^{3}$, Trần Ngọc Mỹ Hoa ${ }^{4}$, Đào Thị Linh Chi và \\ Hoàng Tuấn Long'
}

\section{Thông điệp chính}

- Quyền và hệ thống chuyển quyền carbon vẫn là vấn đề mới mẻ đối với nhiều quốc gia. Cơ chế vận hành của thị trường Các-bon phụ thuộc vào quy mô (thị trường quốc tế hay thị trường nội địa), phạm vi hoạt động (thị trường bắt buộc hay thị trường tự nguyện); hàng hóa giao dịch (tín chỉ bồi hoàn Các-bon hoặc hạn mức phát thải) và phương pháp định giá Các-bon.

- Chuyển quyền Các-bon có thể đi theo 3 phương thức: Quyền Các-bon đi theo quyền và phân loại sở hữu đất công tư; Quyền carbon đi theo mô hình tự chủ và tài sản quốc gia; Quyền carbon đi theo mô hình chia sẻ lợi ích. Phần lớn các nước nghiên cứu tiến hành chuyển quyền Các-bon dựa vào hệ thống luật pháp hiện hành hoặc chọn giải pháp xây dựng quyết định mới. Dù dưới hình thức nào, các quốc gia đều phải làm rõ quyền Các-bon bao gồm những quyền hạn nào (quyền sở hữu đối với Các-bon lưu giữ trong đất và rừng ? quyền hưởng lợi từ việc cung cấp và bán dịch vụ giảm phát thải ? quyền được chuyển nhượng và bán tín chỉ Các-bon/quyền phát thải hay kết hợp của các quyền trên ?) cũng như trách nhiệm (nếu không thực hiện đúng như cam kết thì sẽ phải chịu trách nhiệm gì ?).

- Phần lớn các quốc gia đã nhận chi trả dựa vào kết quả áp dụng mô hình quỹ ủy thác để quản lí tài chính và chia sẻ lợi ích tới các bên có liên quan

- Việt Nam nên (i) tập trung phát triển cả thị trường tự nguyện và thị trường bắt buộc trên quy mô quốc tế và nội địa với các loại hàng hóa hiện có, nhưng ưu tiên phát triển thị trường Các-bon tự nguyện; (ii) gắn kết giữa thị trường Các-bon nội địa với thị trường Các-bon quốc tế; (iii) tối ưu hóa nguồn tài chính để hỗ trợ quá trình thẩm định và bán tín chỉ Các-bon ra thị trường quốc tế; (iv) đa dạng hóa các công cụ và cơ chế chính sách (ví dụ: xây dựng cơ chế thương mại phát thải và thuế Các-bon) cũng sẽ giúp sự vận hành của thị trường Các-bon nội địa được hiệu quả hơn.

\section{Mở đầu}

Giảm phát thải khí nhà kính từ phá rừng và suy thoái rừng (REDD+) được cộng đồng quốc tế và nhiều quốc gia đánh giá là chiến lược quan trọng và hiệu quả

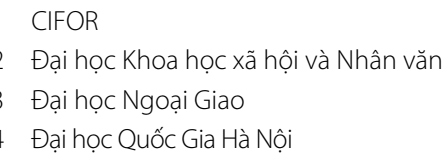

trong cuộc chiến chống biến đổi khí hậu. Chi trả dựa vào kết quả đối với các dự án giảm phát thải nói chung và với các dự án REDD+ nói riêng đã được đề xuất từ năm 2009 và đã có sự cải thiện đáng kể về hệ thống theo dõi, giám sát, thẩm định và đánh giá kết quả làm tiền đề cho chi trả trong 11 năm qua. Tuy nhiên, hiện có rất nhiều quốc gia, trong đó có Việt Nam đang gặp khó khăn trong việc xác định quyền Các-bon, hệ thống chuyển nhượng quyền Các-bon/giấy chứng nhận giảm phát thải cũng như cơ chế quản lí tài chính và chia sẻ lợi ích từ nguồn thu giảm phát thải này. 
Trong năm 2021, Bộ Nông Nghiệp và Phát Triển Nông Thôn (MARD) và Quỹ Bảo Vệ Rừng Việt Nam (VNFF) đã đề nghị Tổ chức nghiên cứu lâm nghiệp quốc tế (CIFOR) hỗ trợ trong việc tổng hợp và phân tích các bài học kinh nghiệm quốc tế liên quan đến các vấn đề chuyển quyền Các-bon và cơ chế chia sẻ lợi ích từ nguồn thu chi trả dựa vào kết quả. Hai báo cáo chuyên đề đã được xuất bản (xin xem thêm Phạm và cộng sự 2021a; Phạm và cộng sự 2021b để biết thêm chi tiết). Tóm lược chính sách này tổng hợp ngắn gọn các kết quả chính mà hai báo cáo chuyên đề này đã chỉ ra đồng thời đưa ra các khuyến nghị để MARD và VNFF xem xét trong quá trình xây dựng cơ chế chính sách liên quan đến vấn đề này.

Dựa vào tài liệu thứ cấp, hai báo cáo (Phạm và cộng sự 2021a; Phạm và cộng sự 2021b) đã nghiên cứu:

- Sự vận hành và định hướng của thị trường Cácbon quốc tế và nội địa trên toàn cầu

- Các quy định quốc tế có liên quan đến quyền Cácbon, chuyển nhượng kết quả giảm phát thải, quản lí tài chính và chia sẻ lợi ích

- Kinh nghiệm của 87 quốc gia trong việc xác định, xây dựng thị trường Các-bon cũng như chính sách liên quan đến quyền và chuyển nhượng quyền Cácbon

- Kinh nghiệm của 52 quốc gia trong việc xây dựng quy trình quản lí tài chính và chia sẻ lợi ích

Từ kết quả nghiên cứu, nhóm tác giả hi vọng sẽ cung cấp một góc nhìn toàn cảnh cũng như bài học để các quốc gia hiện đang hoàn thiện cơ chế chia sẻ lợi ích có thể tham khảo và áp dụng.

\section{Quyền và chuyển quyền Các-bon}

Việc xây dựng hệ thống pháp lí về định nghĩa và chuyển nhượng quyền Các-bon/quyền phát thải là vấn đề mới không chỉ tại Việt Nam mà còn tại nhiều quốc gia trên thế giới. Quá trình xây dựng chính sách liên quan đến vấn đề này thường kéo dài và phụ thuộc vào định hướng phát triển của quốc gia, năng lực của các bên có liên quan cũng như nguồn lực tài chính hiện có. Trong bối cảnh toàn cầu hóa hiện nay, một số vấn mà Việt Nam cần xem xét trong quá trình xây dựng chính sách chuyển quyền Các-bon tại Việt Nam bao gồm:
Việt Nam nên hướng tới thị trường Các-bon bắt buộc hay thị trường Các-bon tựnguyện ?

Rất nhiều câu hỏi được đặt ra bởi các bên có liên quan về vấn đề Việt Nam nên ưu tiên phát triển thị trường Các-bon tự nguyện hay thị trường Các-bon bắt buộc ? Kết quả nghiên cứu của CIFOR cho thấy, trong tương lai các quốc gia đều phải phát triển và hướng tới cả hai thị trường này. Việc chuẩn bị và hướng tới thị trường Các-bon tự nguyện sẽ giúp Việt Nam hoàn thiện hệ thống quản lí hành chính cũng như bán được Các-bon trong khi các thỏa thuận quốc tế về thị trường bắt buộc còn đang được thảo luận chưa đi đến thống nhất. Ngoài ra, các dự án của ngành lâm nghiệp liên quan trồng mới rừng, tái trồng rừng và giảm phát thải từ phá rừng và suy thoái rừng thường dễ dàng thực hiện hơn, có nhu cầu lớn hơn và có nhiều người mua hơn trong thị trường Các-bon tự nguyện. Tuy nhiên tham gia vào thị trường bắt buộc là yếu tố quan trọng để Việt Nam và các nước đạt được mục tiêu đề ra của Thỏa Thuận Paris cũng như giúp Việt Nam tiếp cận với nguồn tài chính quốc tế.

Nếu như việc tham gia vào thị trường tự nguyện đòi hỏi các bên có liên quan (cả trong và ngoài nước) phải đảm bảo đáp ứng các tiêu chuẩn Các-bon tự nguyện tùy vào bên mua là ai thì tham gia vào thị trường Cácbon bắt buộc đòi hỏi sự nhất quán về phương pháp và quy trình quốc tế thông qua bởi các bên tham gia thỏa thuận Paris, đồng thời xây dựng quy trình chính sách mới như các nước đã xây dựng với thị trường Các-bon nội địa bắt buộc của mình.

Trong khi chờ quốc tế thống nhất về luật chơi của Điều khoản 6 trong Thỏa thuận Paris, Việt Nam nên ưu tiên phát triển dự án và kêu gọi đầu tư vào các dự án hướng tới thị trường Các-bon tự nguyện. Ngoài ra Việt Nam cần xem xét để hỗ trợ cả hai mô hình hàng hóa Các-bon: hạn mức phát thải và bồi hoàn Các-bon bởi mỗi loại hàng hóa này đều có lượng lớn người mua tiềm năng đang tìm kiếm trên thị trường trong và ngoài nước.

\section{Kết nối giữa thị trường Các-bon nội địa và thị trường Các-bon quốc tế?}

Cơ chế Chi trả dịch vụ môi trường rừng (PFES) cho Các-bon rừng hiện nay tại Việt Nam thể hiện tiềm năng và cam kết chính trị trong việc vận hành cơ chế Các-bon nội địa, trong đó có sản phẩm Các-bon rừng 
do ngành lâm nghiệp tạo ra. Các chương trình và dự án hiện nay liên quan đến cơ chế Giảm Phát Thải từ Phá rừng và suy thoái rừng (REDD+) cũng cho thấy Việt Nam có quan tâm và định hướng tới thị trường Các-bon quốc tế. Vậy kết nối giữa thị trường Cácbon quốc tế và thị trường Các-bon nội địa này như thế nào? Có sự khác nhau nào giữa hai thị trường này không? Một số vấn đề mà Việt Nam cần xem xét trong quá trình xây dựng chính sách Các-bon rừng nội địa cũng như tiến vào thị trường Các-bon quốc tế là:

\section{Xem xét kết hợp và đa dạng hóa các công cụ chính sách để thành lập thị trường Các-bon nội địa}

Các quốc gia trên thế giới xây dựng thị trường Cácbon nội địa của mình thông qua hình thức: (i) áp dụng thuế Các-bon, (ii) xây dựng cơ chế thương mại phát thải dựa vào việc cấp hạn mức phát thải cho các ngành; (iii) chi trả dịch vụ môi trường Các-bon rừng. Mặc dù hiện nay Việt Nam đang hướng tới giải pháp thứ 3 - PFES- tuy nhiên cũng có thể xem xét bổ sung thêm hai giải pháp còn lại. Một trong những ưu điểm của việc xem xét hai giải pháp thuế Các-bon hoặc xây dựng cơ chế thương mại phát thải hoặc kết hợp cả hai giải pháp này như nhiều nước ở phần trên đã lựa chọn là Việt Nam hoàn toàn áp dụng các tiêu chuẩn Các-bon của thị trường Các-bon quốc tế vào thị trường Các-bon nội địa của mình. Cũng nhờ đó, khi muốn bán tín chỉ Các-bon tạo được trong thị trường Các-bon nội địa của mình, Việt Nam sẽ dễ dàng bán được sản phẩm hiện có hơn vì sản phẩm này cũng đã đáp ứng yêu cầu của quốc tế

\section{Hoàn thiện kết nối giữa thị trường quốc tế và thị trường nội địa}

Việc vận hành PFES dự kiến cho dịch vu Các-bon nội địa hiện nay cũng đặt ra những vấn đề cần phải xem xét để đảm bảo sự khác biệt và gắn kết đối với thị trường Cácbon quốc tế:

Xác định tính bổ sung: đối với việc bán tín chỉ Cácbon ra thị trường quốc tế, điều kiện bắt buộc là phải chứng minh được tính bổ sung (khi có thêm nguồn chi trả thì giá trị bổ sung trong việc tạo ra dịch vụ là bao nhiêu ?). Hiện nay, PFES tại Việt Nam đã có chi trả cho dịch vụ nước, điện và du lịch sinh thái. Việc chi trả dịch cho Các-bon được coi thêm là nguồn thu bổ sung cho cùng một diện tích rừng cung ứng nhiều loại dịch vụ. Tuy nhiên về mặt phương pháp luận, sẽ rất khó có thể chứng minh được tính bổ sung của việc chi trả cho Các-bon sẽ giúp nâng cao chất lượng và số lượng Các-bon bởi trong trường

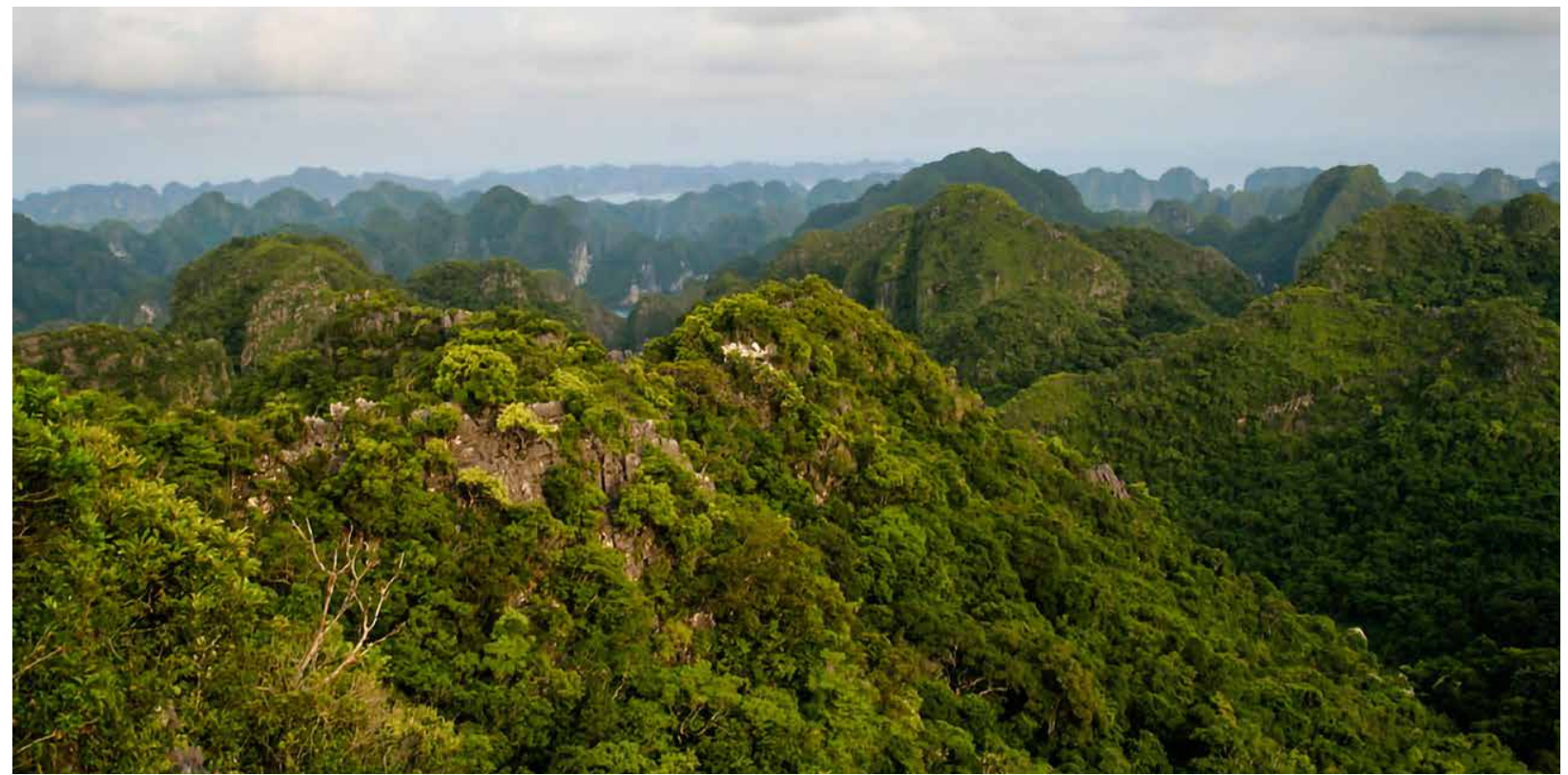

Cảnh quan rừng tại Việt Nam

Ảnh: Terry Sunderland/CIFOR 
hợp không có chi trả cho Các-bon này, với chi trả hiện có cho dịch vụ nước và điện, rừng cũng sẽ cung cấp số lượng và chất lượng Các-bon như vậy. Để giải quyết được vấn đề này, nhiều quốc gia đã phân biệt rõ giữa diện tích rừng tạo ra dịch vụ cũng như đối tượng hưởng lợi của hai thị trường này. Ví dụ, nếu chương trình PES Các-bon nội địa chi trả cho diện tích rừng ở phía Bắc thì chương trình chi trả dựa vào thị trường Các-bon quốc tế (REDD+, FCPF) sẽ chi trả cho diện tích rừng ở phía Nam. Một số nước cũng lựa chọn mở rộng phạm vi của chương trình PES quốc gia. Ví dụ trước đây, với nguồn tài chính từ chương trình PES nội địa chỉ có thể chi trả cho diện tích đất rừng được bảo vệ thì với nguồn tài chính từ thị trường quốc tế sẽ trả thêm cho cả diện tích đất suy thoái hiện đang thực hiện các biện pháp nông lâm kết hợp để biến các diện tích đó thành rừng. Các hoạt động trên sẽ giúp quốc gia dễ dàng hơn trong việc xác định tính bổ sung mà thị trường quốc tế yêu cầu.

\section{Hoàn thiện hệ thống quản lí PFES nội địa - xây} dựng hệ thống đăng kí Các-bon rừng quốc gia để thuận lợi cho viêc tham gia thị trường quốc tế.

Báo cáo này chỉ ra rằng các quốc gia hiện nay trên thế giới, nếu có chương trình PES, đều sử dụng hệ thống này để nhận và phân chia lợi ích và quyền có được từ thương mại Các-bon. Tuy nhiên để làm được điều này hệ thống quản lí PFES nội địa cần phải được hoàn thiện hơn để đón đầu các giao dịch quốc tế. Cụ thể hơn, hệ thống theo dõi giám sát và đánh giá hiện nay chỉ bao gồm diện tích rừng cung ứng dịch vụ môi trường, số lượng người sử dụng, người hưởng lợi. Như các bài học kinh nghiệm của Brazil hay Costa Rica cũng thực hiện PES như Việt Nam cho thấy, hệ thống PES có thể được nâng cấp thành hệ thống đăng kí bán tín chỉ Các-bon hoặc hệ thống đăng kí REDD+ quốc gia nếu bổ sung các thông tin khác bao gồm: trữ lượng Các-bon tạo ra hoặc hấp thụ, diện tích nào do ai chi trả và đã chi trả được bao nhiêu, số series đã được cấp cho tín chỉ Các-bon tạo ra từ diện tích rừng này, số lượng tín chỉ Các-bon đã được cấp và bán cho ai cũng như số lượng Các-bon tiềm năng và số lượng có thể giao dịch trên thị trường quốc tế và nội địa. Việc theo dõi, giám sát và thẩm định này sẽ giúp Việt Nam hay các tỉnh cung cấp thông tin và tín hiệu thị trường rõ ràng hơn đối với người mua trong và ngoài nước cũng như giúp Chính phủ Việt Nam quản lí việc phân bổ hạn mức và quyền Các-bon cũng như đảm bảo tính minh bạch trong việc báo cáo nhằm tránh việc báo cáo và hưởng lợi hai lần của các bên có liên quan. Ngoài ra, việc này cũng giúp Chính phủ xây dựng nhiều phương án thương mại xem bán ở đâu, vào thị trường nào sẽ đem lại hiệu quả cao hơn.

Tối ưu hóa nguồn tài chính để hỗ trợ quá trình thẩm định và bán tín chỉ Các-bon ra thị trường quốc tế. Một diện tích có thể cung cấp lượng tín chỉ Các-bon nhiều hơn số lượng người mua cần. Tuy nhiên, để có thể xác định được chính xác lượng Các-bon mà một diện tích rừng cung cấp được, các bên thẩm định vẫn phải thẩm định giá trị thực tế của cả diện tích rừng này. Việc thẩm định độc lập bởi một bên thứ 3 thường rất tốn kém nhưng lại là yêu cầu bắt buộc mà người mua đặt ra. Do vậy, để tiết kiệm chi phí này, các quốc gia thường tận dụng luôn kết quả thẩm định sẵn có để bán cho nhiều người mua. Ví dụ, một diện tích rừng có thể được thẩm định cung ứng được 20 triệu tấn Các-bon nhưng người mua chỉ mua 6 triệu tấn Các-bon thì cùng lúc đó các quốc gia sẽ đăng thông báo và tìm người mua cho 14 triệu tấn còn lại. Bởi các nhà đầu tư mới có thể tiết kiệm được số tiền bỏ ra cho việc thẩm định, đây là sẽ là ưu điểm tài chính mà nhiều nhà đầu tư quan tâm và hướng tới. Cùng lúc đó Chính phủ cũng có thể giảm được chi phí giao dịch và tăng nguồn thu từ việc này.

\section{Hợp pháp hóa quyền và chuyển quyền Các- bon/chuyển nhượng kết quả giảm phát thải}

Có nhiều phương thức để định nghĩa về quyền Cácbon/quyền chuyển nhượng kết quả giảm phát thải cũng như chuyển nhượng các quyền này (dựa vào hệ thống luật pháp hiện này, xây dựng một chính sách mới, xây dựng một cơ chế chia sẻ lợi ích có liên quan đến chuyển quyền, và các giải pháp kết hợp nhiều phương án). Trong bối cảnh của Việt Nam, Chính phủ dự định sẽ xây dựng một Quyết định của thủ tướng hướng dẫn về điều này. Một số vấn đề cần xem xét trong quá trình này bao gồm:

Hướng dẫn riêng cho từng chương trình đơn lẻ hay là hướng dẫn quốc gia ? Hiện nay, Việt Nam đang xây dựng hướng dẫn riêng cho việc chuyển quyền Các-bon/chuyển nhượng kết quả giảm phát thải 
cho Chương trình Giảm Phát Thải Bắc Trung Bộ. Tuy nhiên, các quốc gia khác không tiếp cận theo quy mô từng chương trình đơn lẻ mà hướng tới mục tiêu xây dựng một quy định và hướng dẫn chung quốc gia, áp dụng cho tất cả chương trình bao gồm chương trình ERPA. Việc xây dựng hướng dẫn chung quốc gia này sẽ đảm bảo tính thống nhất và nhất quán về mặt luật pháp giữa các chương trình đồng thời tiết kiệm chi phí và nguồn lực của các bên có liên quan.

\section{Ai nên là người sở hữu quyền Các-bon và có trách nhiệm phân bổ quyền này cho các bên có liên quan ? Có 2 cách tiếp cận của các nước liên quan đến vấn đề này:}

- Quyền Các-bon đi theo quyền và phân loại sở hữu đất công tư. Đối với diện tích rừng do nhà nước quản lí, Nhà nước sở hữu quyền Các-bon tạo ra trên diện tích rừng này. Đối với diện rừng do các bên ngoài nhà nước quản lí, toàn quyền Các-bon cũng thuộc về chủ sở hữu ngoài nhà nước này. Điều này tạo điều kiện khuyến khích các bên ngoài nhà nước tham gia vào các hoạt động thương mại giảm phát thải nhưng trong thực tế không phải nhóm chủ sở hữu rừng nào cũng có đủ năng lực để làm điều này (đặc biệt cộng đồng dân cư) do vậy vẫn cần sự hỗ trợ của nhà nước.

- Quyền tự chủ và tài sản quốc gia. Mặc dù theo loại hình sử dụng đất có sở hữu công và sở hữu tư, nhưng với mục tiêu đảm bảo quyền tự chủ và tài sản quốc gia, quyền Các-bon chỉ thuộc về nhà nước. Các bên ngoài nhà nước có quyền hưởng lợi từ việc bán cây đứng, quyền sử dụng lâm sản, quyền chuyển giao các tài sản liên quan đến gỗ và dịch vụ môi trường nhưng không có quyền sở hữu hoặc chuyển giao quyền Các-bon. Nói cách khác, quyền Các-bon được tách ra khỏi các quyền hưởng lợi hiện nay của các chủ rừng này. Tuy nhiên, Nhà nước có thể kí chuyển nhượng quyền cho các bên có liên quan. Các kết quả nghiên cứu từ báo cáo này cho thấy trong trường hợp quyền Các-bon thuộc về quốc gia, các quốc gia hoặc sẽ phê chuẩn một Bộ ngành cụ thể (Bộ Tài Chính - nơi quản lí dòng tài chính liên quan đến thương mại phát thải; hoặc Bộ Ngoại Giao - đơn vị quy định hướng dẫn các hoạt động đối với quốc tế - hoặc Bộ Môi trường/ Bộ Nông Lâm Nghiệp chịu trách nhiệm hướng dẫn điều phối các hoạt động kĩ thuật giảm phát thải). Việc lựa chọn Bộ ngành nào chịu trách nhiệm phụ thuộc rất nhiều vào chức năng nhiệm vụ được giao của mỗi nước, cũng như năng lực và sức mạnh ảnh hưởng của các bên này trong quá trình đàm phán.

- Mô hình chia sẻ lợi ích. Cơ chế chia sẻ lợi ích đóng vai trò quan trọng trong việc quyết định quyền Các-bon thuộc về ai. Có 3 phương án chính liên quan đến hệ thống chia sẻ lợi ích và chuyển quyền Các-bon mà các quốc gia đang áp dụng: i) cơ chế chia sẻ lợi ích ở quy mô quốc gia - trong đó Chính quyền trung ương (đại diện bởi một Bộ hoặc cơ quan nhà nước cụ thể) là nơi toàn quyền điều phối và phân bổ lợi ích tới các bên hưởng lợi; (ii) cơ chế chia sẻ lợi ích theo quy mô quốc gia nhưng được thực hiện và đóng góp bởi chính quyền cấp địa phương kết hợp với các chương trình dự án; (iii) cơ chế chia sẻ lợi ích theo mô hình dự án và chương trình. Đối với trường hợp (ii) và (iii) nhà nước sẽ phải làm rõ quá trình chuyển quyền Các-bon.

Phương án 2 được phần lớn quốc gia lựa chọn để đảm bảo tính tự chủ của chính quyền quốc gia,tiết kiệm chi phí và nguồn lực giao dịch trong việc thiết kế, giám sát và điều hành đồng thời hạn chế các rủi ro trong khiếu kiện (càng nhiều bên sở hữu quyền Các-bon càng có nhiều tiềm năng tranh chấp trong vấn đề hưởng lợi. Tuy nhiên, nếu chỉ có một sở hữu chính phân bổ lại quyền Các-bon qua hệ thống giấy chứng nhận và cấp phép sẽ giảm đi các xung đột). Các nước chỉ chọn phương án 1 khi hệ thống sở hữu tư phát triển mạnh mẽ và là trụ cột của chính trị quốc gia, có mâu thuẫn xung đột xã hội lớn giữa các bên có liên quan, các cơ quan nhà nước và ngoài nhà nước đạt được thỏa thuận trong cơ chế chia sẻ lợi ích và cấp chứng chỉ quyền Các-bon thuận lợi.

Từ kết quả phân tích chính sách hiện hành tại Việt Nam, Bộ Nông Nghiệp Và Phát Triển Nông Thôn (Bộ NN-PTNT) đang xem xét giải pháp Ủy Ban Nhân Dân các tỉnh sẽ chuyển quyền Các-bon với vai trò là chủ sỡ hữu tài sản ở cấp tỉnh cho Bộ NN-PTNT (chính quyền trung ương và là bên thực hiện dự án) trong khuôn khổ của Chương trình giảm thải Bắc Trung Bộ. Phương án này, nếu áp dụng cho khuôn khổ 
chương trình ERPA như một dự án thì sẽ phù hợp với xu thế các nước đang lựa chọn, đó là cơ quan nhà nước sở hữu toàn bộ quyền Các-bon. Tuy nhiên, có hai vấn đề cần xem xét:

\section{- Bộ NN-PTNT là bên cấp hay bên nhận quyền ?} Như đã trình bày ở trên, việc xây dựng một quyết định cho một dự án hay chương trình đơn lẻ có rất nhiều hạn chế mà cần tiến tới việc xây dựng một quy định chung cho toàn quốc gia mà mọi chương trình dự án đều phải thuân thủ để đảm bảo tính thống nhất. Trong trường hợp này, theo mô hình các quốc gia khác đang áp dụng, Bộ NN-PTNT không chỉ đóng vai trò là bên thực hiện Chương trình mà còn là đại diện của Nhà nước Việt Nam sở hữu và có quyền chuyển giao quyền Các-bon và giảm phát thải Các-bon rừng. Nói cách khác, Bộ NN-PTNT, đại diện cho Chính phủ Việt Nam sẽ cấp phép quyền giảm phát thải cho các bên (chính quyền tỉnh, các dự án, etc.) qua một quy trình đăng kí và cấp phép riêng chứ không phải nhận giấy ủy quyền của chính quyền cấp tỉnh.

- Nếu trong trường hợp UBND tỉnh chuyển quyền cho Bộ NN-PTNT trong khuôn khổ dự án, họ sẽ chuyển quyền bao nhiêu tín chỉ Các-bon/kết quả giảm phát thải hay tất cả ? Nếu đi theo giải pháp Bộ Nông Nghiệp và Phát Triển Nông Thôn cấp phép quyền Các-bon, kết quả phát thải đã được xác định và dễ dàng phân bổ. Trong trường hợp UBND tỉnh chuyển quyền Các-bon về Bộ NN-PTNT, UBND sẽ phải nêu rõ quyền Các-bon với bao nhiêu lượng Các-bon sẽ chuyển trong dự án này. Tuy nhiên, vì còn phải trải qua quá trình thẩm định nên chưa rõ con số này là bao nhiêu, đồng thời nếu tiến hành theo quy mô dự án thì Tỉnh sẽ phải gửi lại cho Bộ giấy chuyển quyền Các-bon khác trong dự án mới. Điều này không những gây khó khăn trong việc hoàn thiện giấy phép chuyển quyền mà tạo ra chi phí giao dịch cao.

Chuyển quyền Các-bon và đóng góp vào NDC. Một điểm quan trọng cần cân nhắc đó là việc chuyển quyền Các-bon sẽ có ảnh hưởng thế nào tới việc quốc gia thực hiện cam kết NDC. Trong thực tế, nhiều bên mua quyền giảm phát thải để thực hiện cam kết NDC của quốc gia này. Do quy định của Thỏa Thuận Paris không được tính hai lần nên nếu đã bán cho nước ngoài thì Việt Nam không có quyền báo cáo kết quả giảm phát thải này vào kết quả thực hiện NDC của mình. Nếu đặt mục tiêu thực hiện NDC là ưu tiên, cần tính toán cụ thể cần bao nhiêu lượng phát thải của ngành lâm nghiệp để đảm bảo cam kết NDC cũng như bao nhiêu lượng Các-bon có thể chuyển quyền mà không ảnh hưởng đến cam kết tự nguyện quốc gia.

\section{Xây dựng năng lực cho hệ thống đăng kí và chuyển} quyền Các-bon. Các quốc gia đều thiết lập và nâng cao năng lực cho một cơ quan nhà nước làm đầu mối trong việc đăng kí, chuyển quyền Các-bon, thẩm định và giải quyết các tranh chấp có liên quan đến quá trình đăng kí và chuyển quyền Các-bon. Cơ quan này sẽ hoạt động dựa trên một phần ngân sách nhà nước cũng như từ phí hành chính và quản lí có được từ các bên nộp đăng kí cấp phép, cũng như từ việc tiến hành các hoạt động thẩm định, và giám sát.

\section{Quyền phải đi đôi với trách nhiệm. Kết quả nghiên} cứu trong báo cáo cho thấy, các chính sách liên quan đến chuyển quyền Các-bon phải gắn kết giữa quyền hạn và trách nhiệm. Các quyền hạn và lợi ích được giao cho các bên nhưng nếu các bên không thực hiện đúng chức năng nhiệm vụ và cam kết giảm phát thải của mình thì phải chịu những hình phạt. Ví dụ như các cơ chế thương mại phát thải tại các nước Châu Âu quy định, các bên có quyền hưởng lợi từ việc mua bán giảm phát thải nhưng nếu không đạt được mục tiêu đề ra sẽ phải nộp phạt tài chính đồng thời chịu những trách nhiệm hình sự theo quy định. Điều này để đảm bảo tính hiệu quả của các chương trình và chính sách giảm phát thải.

\section{Cơ chế quản lí tài chính và chia sẻ lợi ích}

Khi xây dựng chính sách và cơ chế chia sẻ lợi î́ch, các nhà hoạch định chính sách trên toàn cầu thường đặt ra 4 câu hỏi chính: Chi phí và lợi ích để thực hiện cơ chế này là gì ? Ai là người thụ hưởng ? Cơ cấu tổ chức thế nào ? (quy mô, loại hình tài chính) và lợi ích sẽ được phân bổ ra sao (tiêu chí chi trả/phân bổ lợi ích, các bước chi trả, hình thức chi trả, thời gian và tần suất chi trả); và các biện pháp đảm bảo an toàn sẽ được thiết kế ra sao để hỗ trợ quá trình chia sẻ lợi 
ích (ví dụ như đảm bảo minh bạch thông tin và có sự tham gia của người dân).

Chi phí là lợi ích. Trong khi các chương trình dự án trên toàn cầu chỉ phần lớn tập trung vào phân chia lợi ích, không có quốc gia nào xem xét và đánh giá đầy đủ cả 4 loại chi phí: (i) chi phí thực hiện (ví dụ- phí cho việc giám sát, đánh giá, xây dựng chính sách mới, đào tạo nhân lực, chi trả tiền lương, đi lại); (ii) chi phí giao dịch (chi phí có liên quan đến việc tiến hành các giao dịch thương mại ví dụ chi phí để kí hợp đồng, bán tín chỉ Các-bon trên thế giới, họp hành thương thảo giữa người mua và người bán); (iii) chi phí cơ hội (lợi î́ch và thiệt hại kinh tế khi thay thế một loại hình sử dụng đất. Chi phí cơ hội có thể được tính trên mỗi tấn Các-bon tạo ra, hoặc trên mỗi ha đất hoặc trên mỗi một đối tượng tham gia vào cơ chế chi trả) và (iv) chi phíxã hội (chi phí xã hội phải bỏ ra để thực hiện chương trình) khi thiết kế hệ thống chia sẻ lợi ích của mình. Có thể nói tất cả các chương trình hay chính sách chia sẻ lợi ích cho tới nay mới chỉ áp dụng tỉ lệ \% (từ 4\% - 25\%) để đề phân bổ cho các chi phí thực hiện và quản lí chương trình. Tuy các quốc gia đều xem xét tới chi phí cơ hội nhưng lại không dùng thông số này để thiết kế mức chi trả cho phù hợp, bởi chi phí cơ hội thường cao hơn rất nhiều so với mức chi trả mà chương trình giảm phát thải có thể đáp ứng. Cả chi phí và lợi ích liên quan đến việc thực hiện chính sách cũng như hoạt động giảm phát thải và cơ chế chia sẻ lợi ích cần được phân tích để hiểu rõ về cả tác động tích cực và tiêu cực đối với các chủ thể và người hưởng lợi; từ đó xây dựng cơ chế tối đa hóa các tác động tích cực và giảm thiểu tối đa các tác động tiêu cực nếu có thể.

\section{Ai là người thụ hưởng ? Kết quả nghiên cứu cho} thấy hiện nay các quốc gia đang áp dụng chi trả cho một tổ hợp nhiều nhóm người hưởng thụ bao gồm: (i) những người có quyền hợp pháp (dù theo luật định hay theo tập quán) đối với những lợi ích phát sinh từ rừng và dịch vụ môi trường rừng; (ii) các bên quản lý rừng thực hiện các hoạt động phát thải thấp; (iii) các bên hỗ trợ thực hiện hiệu quả các hoạt động giảm phát thải (ví dụ các bên trung gian, người kết nối thị trường, chương trình dự án, NGOs, các cơ quan chính phủ ở các cấp); (iv) nhóm người nghèo và nhóm dễ bị tổn thương để đảm bảo những tác động xã hội tích cực mà chương trình đem lại, (v) Chính phủ và dựán nên phân bổ các lợi ích REDD + để bù đắp cho các bên vì thực hiện các hoạt động giảm phát thải mà phải chịu nhiều loại chi phí và thiệt hại.

Cơ cấu quản lí tài chính và chia sẻ lợi ích. $58.3 \%$ các quốc gia đã nhận được ERPA coi tiền thanh toán từ chi trả giảm phát thải là nguồn thu của ngân sách nhà nước và chuyển tới một Bộ Ngành cụ thể để quản lí. 58.3\% chọn mô hình chuyển tiền tới Quỹ Ủy Thác môi trường độc lập (có thể đặt trụ sở ở trong hoặc ngoài nước). Các nước không tham gia vào Quỹ Các-bon và kí thỏa thuận thương mại giảm phát thải (ERPA) nhưng kí thỏa thuận song phương với Na Uy hay các nhà tài trợ khác cũng có xu thế chung khi quản lí nguồn thu từ việc bán Các-bon bằng 4 mô hình chung: (i) Chuyển tới Quỹ môi trường khác được quản lí ở cấp quốc gia hoặc quốc tế, (ii) Chuyển tới bên trung gian thị trường và NGO; (iii) Chuyển tới ngân sách nhà nước và các bộ ngành; (iv) Chuyển tới Quỹ môi trường tại cấp khu vực và cấp tỉnh. Báo cáo chỉ ra rằng, 5 yếu tố ảnh hưởng chính tới quyết định của quốc gia trong việc lựa chọn phương thức quản lí tài chính và chia sẻ lợi ích là: (i) khoản thu là lớn hay nhỏ; (ii) quy định của nhà tài trợ; (iii) khuôn khổ pháp lí quốc gia về quản lí tài chính từ nguồn thu nước ngoài và (iv) năng lực quản lí tài chính hiện có của các bên có liên quan); (v) ý kiến và sự đồng thuận của các bên có liên quan. Ngoài ra, các nước có sự tương đồng cao về tiêu chí đánh giá xác thực một bên có đủ điều kiện nhận được tiền chi trả hay không. Cụ thể hơn, các tiêu chí này bao gồm các hoạt động đóng góp vào giảm phát thải (chỉ tiêu môi trường); đóng góp vào đảm bảo tác động tích cực đối với xã hội (chỉ tiêu xã hội) và hoàn thành trách nhiệm của các bên quản lí và trung gian. Tuy nhiên, mỗi quốc gia lại có cách tiếp cận riêng trong việc áp dụng các tiêu chí này riêng lẻ hoặc kết hợp. Mặc dù tần suất chi trả được coi là vấn đề thiết yếu trong cơ chế chia sẻ lợi ích, các quốc gia đều không cụ thể hóa điều này trong các văn kiện dự án hay chính sách cụ thể về chia sẻ lợi ích mà phần lớn dựa trên kết quả của quá trình tham vấn và thương thảo với các bên có liên quan. Ngoài ra, tuy cùng phải thực hiện các yêu cầu quốc tế giống nhau, một số quốc gia (Costa Rica) đã có hệ thống chia sẻ lợi ích với tính năng khác biệt lớn so với các nước khác bao gồm làm rõ hoạt động nào, ở đâu, được phép và không được phép và đa dạng hóa nhiều hình thức chuyển tiền cho nhiều đối tượng.

Các biện pháp đảm bảo an toàn. Cơ chế chia sẻ lợi ích cũng như các biện pháp bảo đảm an toàn phải phù 
hợp với bối cảnh quốc gia và phải được xây dựng dựa trên đánh giá rủi ro để thiết lập mức độ ưu tiên, xem xét dữ liệu hiện có (và có thể truy cập được), năng lực của các bên có liên quan và thể chế hiện hành. Các quốc gia hiện đang phải đối mặt với 3 thách thức lớn trong việc liên kết cơ chế chia sẻ lợi ích với hệ thống thông tin về biện pháp bảo đảm an toàn, bao gồm (i) hạn chế cả nguồn lực tài chính lẫn nguồn lực con người, (ii) sự chồng chéo giữa các tiêu chuẩn về biện pháp đảm bảo an toàn; (iii) bình đẳng giới vẫn tiếp tục là một vấn đề bị xem nhẹ. Tuy nhiên, kết quả phân tích cũng cho thấy một số quốc gia đã có những sáng kiến được cộng đồng quốc tế đánh giá cao, đặc biệt trong việc đảm bảo và nâng cao tác động xã hội như Costa Rica khi xây dựng cơ chế hưởng lợi riêng cho những người không có chứng nhận quyền sử dụng đất hay Guatemala trong việc áp dụng tiêu chí đoàn kết (một tỉnh trong khu vực có hiện tượng giảm phát thải thì toàn bộ các tỉnh lân cận phải cùng chịu trách nhiệm) để giảm thiểu tối đa rủi ro dịch chuyển phát thải.

\section{Kết luận}

Việt Nam đã có nhiều khung pháp lí liên quan đến bảo vệ môi trường và phát triển bền vứng. Tích hợp và xem xét các bài học quốc tế phù hợp với bối cảnh Việt Nam sẽ giúp quốc gia xây dựng các phương án phù hợp. Cơ chế chia sẻ lợi ích và chuyển quyền Các-bon chỉ thực sự thành công khi phản ánh tiếng nói và đảm bảo lợi ích của các bên liên quan và phải phù hợp với bối cảnh cụ thể của quốc gia / địa phương. Các chính sách và dự án giảm phát thải cũng như cơ chế chia sẻ lợi ích không hoạt động riêng lẻ mà được vận hành cùng một lúc và song song với nhiều chương trình chính trị, kinh tế, môi trường và xã hội khác và do vậy cần phải hài hòa hóa với các chính sách này. Tuy Việt Nam không thể áp dụng tất cả các bài học và mô hình chia sẻ lợi ích mà các quốc gia khác đang áp dụng nhưng bài học kinh nghiệm từ các nước này đã chỉ ra một số nguyên tắc hướng dẫn chính có thể giúp Việt Nam hoàn thiện cơ chế chính sách liên quan.

\section{Lời cảm ơn}

Chúng tôi xin gửi lời cảm ơn tới Cơ quan Phát triển Quốc tế Hoa Kỳ (USAID) và Cơ quan Hợp tác Phát triển $\mathrm{Na}$ Uy (NORAD) đã tài trợ cho nghiên cứu này.

\section{Tài liệu tham khảo}

Pham TT, Nguyen VA, Nguyen TA, Tran NMH, Dao TLC, Hoang TL. 2021a. Kinh nghiệm của 87 quốc gia trong việc xác định và chuyển nhượng quyền Các-bon. Báo cáo chuyên đề của CIFOR, Bogor, Indonesia.

Pham TT, Nguyen VA, Nguyen TA, Tran NMH, Dao TLC, Hoang TL. 2021b. Cơ chế quản lí tài chính và chia sẻ lợi ích liên quan đến chi trả dựa vào kết quả giảm phát thải tại 54 quốc gia trên thế giới. Báo cáo chuyên đề của CIFOR, Bogor, Indonesia.

\begin{tabular}{|l|l|l|l|l} 
Chương trình nghiên cứu của CGIAR về Rừng, Cây gỗ và Nông lâm kết hợp (FTA) là chương trình phát \\
triển nghiên cứu lớn nhất thế giới nhằm nâng cao vai trò của rừng, cây gỗ và nông lâm kết hợp với \\
mục tiêu phát triển bền vững và đảm bảo lương thực để ứng phó với biến đổi khí hậu. CIFOR chủ trì \\
các nghiên cứu FTA trong mối quan hệ đối tác chiến lược với Bioversity International, CATIE, CIRAD, \\
INBAR, ICRAF và TBI. \\
Nghiên cứu này được hỗ trợ bởi Quỹ đối tác CGIAR: cigar.org/funders/ \\
PROGRAM on \\
$\begin{array}{l}\text { Forests, Trees and } \\
\text { Agroforestry }\end{array}$
\end{tabular}
nghiên cứu sáng tạo, nâng cao năng lực của các bên đối tác, tích cực tham gia đối thoại với các bên liên quan để hỗ trợ định hình chính sách và thực tiễn tác động tới rừng và con người. CIFOR là tổ chức nghiên cứu thuộc liên minh CGIAR và chủ trì các chương trình nghiên cứu của CGIAR về Rừng, Cây gỗ và Nông lâm kết hợp (FTA). Trụ sở chính của CIFOR đặt tại Bogor, Indonesia và các văn phòng của CIFOR có mặt tại Nairobi, Kenya; Yaounde, Cameroon; Lima, Peru và Bonn, Germany. 